\title{
MANAJEMEN PEMASARAN JASA PENDIDIKAN BERBASIS BUDAYA RELIGIUS
}

\author{
Afif Alfiyanto \\ Program Studi Manajemen Pendidikan Islam UIN Raden Fatah Palembang \\ e-mail: afifalfiyanto_uin@radenfatah.ac.id
}

\begin{abstract}
In general, this study aims to determine the marketing management of religious culture-based education services at SDIT Luqman Al-Hakim International Yogyakarta. In addition, this study intends to determine the importance of marketing management of religious culture-based education services at SDIT Luqman Al-Hakim International Yogyakarta. This research applied a qualitative field method. The samples were determined using purposive sampling and snowball techniques. The data were collected using interview, observation, and documentation techniques. In this study, the researcher used a descriptive-qualitative data analysis technique with an inductive approach to analyze the data. The results of this study indicated that: (1) SDIT LHI conducts marketing management based on religious culture to fulfill the needs of education customers who will build a generation of Muslims that has strong and noble characters, masters the principles, has scientific basis, contributes to the good of the world, and is devoted to Allah SWT. There are 7 elements used in marketing management, namely: 1) Product, 2) Price; 3) place; 4) Promotion; 5) Human Resource; 6) Physical Evidence; 7) Process. (2) The implementation of religious culture is carried out by school through the dimensions of monotheism, the Shari'ah, and morality contained in the curriculum, vision, mission, school purpose, school programs, and the learning process. (3) Factors that support the marketing of education services at SDIT LHI, which are a. Application of PHI curriculum; $b$. Competent human resources; $c$. Complete educational facilities; $d$. Promotional activities that use many strategies; e. Easily accessible school locations; and f. A lot of achievements in the public and religious fields. Meanwhile, the inhibiting factors are a. The lack of student input due to fairly expensive tuition fees; $b$. Temporary teaching staff; $c$. Competition with other educational institutions; $d$. Marketing management lacks employees; $e$. Different interpretations of school purposes by school administrators and parents.
\end{abstract}

Keywords; Marketing management, religious culture.

\section{PENDAHULUAN}

Abad ke-21 yang dikenal dengan era globalisasi memiliki dampak perubahan yang sangat cepat dalam masyarakat. Perkembangan teknologi informasi yang sangat cepat berdampak pada hubungan antar negara di dunia tanpa batas, sehingga terjadinya persaingan sangat ketat antar bangsa dalam segala lini kehidupan, termasuk di dalamnya pendidikan. Pesatnya pertumbuhan lembaga-lembaga pendidikan yang cenderung meningkat di satu sisi memang sesuai dengan hasrat untuk meratakan kesempatan memperoleh pendidikan bagi generasi muda. Namun di sisi lain perlu memperhatikan peningkatan mutu dan efisiensi.

Saat ini paradigma masyarakat dalam memandang pendidikan mulai mengalami pergeseran. Awalnya pendidikan dikaji dari aspek sosial, namun sekarang orang melihat pendidikan lebih pada perusahaan (corporate). Lembaga pendidikan diartikan sebagai suatu organisasi produksi yang menghasilkan jasa pendidikan yang dibeli oleh konsumen. Produsen yang 
tidak mampu memasarkan jasa pendidikan disebabkan karena mutunya tidak memuaskan konsumen, maka produksi jasa pendidikan yang pasarkan tidak akan laku di pasaran.

Memahami perilaku konsumen adalah permasalahan mendasar saat menentukan strategi pemasaran. Mengenali perilaku konsumen akan membuat pengelola sekolah mengetahui karakteristik konsumen, bagaimana konsumen membuat keputusannya serta berbagai faktor yang mempengaruhi perilaku mereka dalam mengambil keputusan atas pembelian suatu produk atau jasa.

Kotrel dan Amstrong ${ }^{1}$ mendefinisikan pemasaran sebagai sebuh proses sosial dan manajerial yang membuat individu dan kelompok memperoleh apa yang mereka butuhkan dan inginkan, lewat penciptaan dan pertukaran timbal balik produk dan nilai dengan orang lain. Pemasaran juga diartikan proses sosial dan manajerial yang mana individu dan kelompok memperoleh apa yang mereka butuhkan dan inginkan dengan cara menciptakan serta mempertukarkan produk dan nilai dengan pihak lain².

Hakikatnya bila lembaga pendidikan dipandang melalui kacamata corporate, maka lembaga pendidikan ini adalah organisasi produk yang menghasilkan jasa pendidikan yang dibeli dari konsumen. Konsumen dalam kamus besar bahasa Indonesia bias diartikan sebagai pengguna jasa atau pelanggan. Pelanggan pendidikan adalah orang yang menggunakan jasa lembaga pendidikan untuk memenuhi kebutuhan mereka dan kelangsungan lembaga pendidikan sangat bergantung pada pelanggan ${ }^{3}$.

Pemasaran dalam konteks jasa pendidikan adalah sebuah proses sosial dan manajerial untuk mendapatkan apa yang dibutuhkan dan diinginkan melalui penciptaan (creation) penawaran, pertukaran produk yang bernilai dengan pihak lain dalam Pendidikan ${ }^{4}$. Proses pemasaran dipengaruhi oleh berbagai faktor, salah satunya adalah faktor budaya. Akibatnya setiap individu atau kelompok mempunyai kebutuhan dan keinginan dengan menciptakan, menawarkan, dan menukarkan produk yang bernilai komoditas. Kebutuhan masyarakat Indonesia yang mayoritas beragama Islam, khususnya dalam dunia pendidikan adalah pendidikan moral. Tantangan abad ke21 yang semakin kompleks dan dinamik mempunyai efek positif dan negatif. Efek negatif yang di akibatkan salah satunya adalah kemerosotan moral anak bangsa yang semakin hari semakin jauh dari nilai-nilai keislaman.

\footnotetext{
${ }^{1}$ Sihombing 2001)

${ }^{2}$ M Taufiq Amir, "Dinamika Pemasaran," Jakarta: PT. Raja Grafindo Persada (2005).

${ }^{3}$ Buchari Alma and Ratih Hurriyati, Manajemen Corporate \& Strategi Pemasaran Jasa Pendidikan (Alfabeta, 2008).

${ }^{4}$ Ara Hidayat and Imam Machali, "Pengelolaan Pendidikan: Konsep, Prinsip, Dan Aplikasi Dalam Mengelola Sekolah Dan Madrasah” (Kaukaba, 2012).
} 
Krisis moral tersebut tidak hanya melanda masyarakat lapisan bawah (grass root), tetapi juga meracuni atmosfer birokrasi negara mulai level paling atas sampai paling bawah ${ }^{5}$. Realitas tersebut menimbulkan berbagai pertanyaan mengenai efektivitas pendidikan agama yang selama ini dipandang oleh sebagian besar masyarakat Indonesia telah gagal dalam membentuk kepribadian siswa dengan nilai-nilai agama serta mampu menjawab tantangan zaman.

Fenomena tersebut tidak terlepas dari adanya pemahaman yang kurang benar tentang agama dan keberagamaan (religiusitas). Agama sering kali dimaknai secara dangkal, tekstual dan cenderung eksklusif. Nilai-nilai agama hanya dihafal sehingga hanya berhenti pada wilayah kognisi, tidak sampai menyentuh aspek afeksi dan psikomotorik. Nilai religius adalah nilai-nilai kehidupan yang mencerminkan tumbuh-kembangnya kehidupan beragama yang terdiri dari tiga unsur pokok yaitu aqidah, ibadah dan akhlak yang menjadi pedoman perilaku sesuai dengan aturanaturan illahi untuk mencapai kesejahteraan serta kebahagiaan hidup di dunia dan akhirat ${ }^{6}$.

Menurut Kotter dan Hasket $^{7}$ budaya adalah totalitas pola perilaku, kesenian, kepercayaan, kelembagaan, dan semua produk lain dari karya dan pemikiran manusia yang mencirikan kondisi suatu masyarakat atau penduduk yang ditransmisikan bersama. Pengertian Budaya menurut Montago dan Dawson ${ }^{8}$ merupakan way of life, yaitu cara hidup tertentu yang memancarkan identitas tertentu pula dari suatu bangsa. Kemudian Kotter dan Hasket mendefinisikan kebudayaan secara formal sebagai suatu keseluruhan dari pola perilaku yang dikirimkan melalui kehidupan sosial, seni, agama, kelembagaan dan segala hasil kerja dan pemikiran manusia dari suatu kelompok manusia.

Budaya religius mengacu pada idenitifikasi akibat-akibat keyakinan kegamaan, praktik, pengalaman, dan pengetahuan seseorang dari hari ke hari. Berkaitan dengan dimensi pengetahuan agama yang mengacu kepada harapan bahwa orang-orang yang beragama, paling tidak memiliki sejumlah minimal pengetahuan, antara lain mengenai dasar-dasar tradisi. Tradisi memiliki beberapa fungsi, yaitu (1) Tradisi sebagai wadah ekspresi keagamaan; dan (2) Tradisi sebagai alat pengikat kelompok $^{9}$.

Budaya religius sekolah merupakan cara berfikir dan cara bertindak warga sekolah yang didasarkan atas nilai-nilai religius (keberagamaan). Religius menurut Islam adalah menjalankan ajaran agama secara menyeluruh. Nilai religius merupakan dasar dari pembentukan budaya religius, karena tanpa adanya penanaman nilai religius, maka budaya religius tidak akan

\footnotetext{
${ }^{5}$ Asmaun Sahlan, Mewujudkan Budaya Religius Di Sekolah: Upaya Mengembangkan PAI Dari Teori Ke Aksi (UIN-Maliki Press, 2010).

${ }^{6}$ Ibid.

${ }^{7}$ Faturrohman 2015)

${ }^{8}$ Daryanto 2015)

${ }^{9}$ Muhaimin et al., Paradigma Pendidikan Islam: Upaya Mengefektifkan Pendidikan Agama Islam Di Sekolah (Remaja Rosdakarya, 2001).
} 
terbentuk ${ }^{10}$. Tanpa adanya nilai maka tidak akan terbentuk sebuah budaya religius karena nilai sebagai pondasi terbentuknya budaya religius. Budaya religius bukan sekedar suasana religius, namum budaya relgius adalah suasana religius yang telah menjadi kebiasaan sehari-sehari ${ }^{11}$.

Berdasarkan hasil penelusuran yang dilakukan peneliti, penelitian yang akan dilakukan memiliki kemiripan dan keterkaitan dengan penelitian-penelitian terdahulu, diantaranya: (1) Jurnal yang ditulis oleh Imam Faizin tentang "Strategi Pemasaran Jasa Pendidikan Dalam Meningkatkan Nilai Jual Madrasah"12 (2) Jurnal yang ditulis oleh M. Munir tentang "Manajemen Pemasaran Pendidikan Dalam Meningkatkan Kuantitas Peserta Didik"13; dan (3) Jurnal yang ditulis oleh Sarifudin dan Rehendra Maya tentang "Implementasi Manajemen Pemasaran Jasa Pendidikan Dalam Meningkatkan Kepuasan Pelanggan Di Madrasah Aliyah Terpadu (Mat) Darul Fallah Bogor"14.

Peneliti melakukan penelitian tentang "Manajemen Pemasaran Jasa Pendidikan Berbasis Budaya Religius di SDIT Luqman Al-Hakim Internasional Yogyakarta”. Tema penelitian yang diteliti oleh peneliti tentunya memiliki perbedaan dengan penelitian sebelumnya. Fokus peneliti adalah manajemen pemasaran jasa pendidikan berbasis budaya religius yang belum pernah diteliti sebelumnya, terutama mengenai konsep manajemen pemasaran jasa pendidikan berbasis budaya religius dan lokasi penelitian yang berlokasi di SDIT Luqman Al-Hakim Internasional Yogyakarta. Sehingga penelitian yang dilakukan peneliti adalah baru dan belum pernah diteliti sebelumnya.

\section{METODE}

Jenis penelitian ini adalah penelitian field Research yaitu penelitian lapangan yang bersifat kaulitatif. Penelitian kualitatif yaitu suatu penelitian yang ditunjukkan untuk mendeskripsikan dan menganalisa fenomena, peristiwa, aktivitas sosial, sikap, kepercayaan, persepsi, pemikiran orang secara individu maupun kelompok. Metode yang digunakan adalah deskritif-kualitatif yaitu upaya untuk mengupas secara medalam dengan tujuan menemukan fakta di lapangan.

Sumber data dalam penelitian ini terbagi menjadi dua, yaitu dokumen dan wawancara. Dokumen yang dijadikan sumber data berupa visi, misi, kurikulum, latar belakang sekolah,

\footnotetext{
${ }^{10}$ Faturrohman, "Budaya Religius Dalam Peningkatan Mutu Pendidikan: Tinjauan Teoritik Dan Praktik Kontekstualisasi Pendidikan Agama Di Sekolah.”

${ }^{11}$ Chusnul Chotimah and Muhammad Fathurrohman, "Komplemen Manajemen Pendidikan Islam: Konsep Integratif Pelengkap Manajemen Pendidikan Islam” (Teras, 2014).

${ }^{12}$ Imam Faizin, "Strategi Pemasaran Jasa Pendidikan Dalam Meningkatkan Nilai Jual Madrasah," Madaniyah 7, no. 2 (2017).

${ }^{13}$ M Munir, "Manajemen Pemasaran Pendidikan Dalam Peningkatan Kuantitas Peserta Didik," Intizam, Jurnal Manajemen Pendidikan Islam 1, no. 2 (2018): 78-94.

${ }^{14}$ Sarifudin Sarifudin and Rahendra Maya, "Implementasi Manajemen Pemasaran Jasa Pendidikan Dalam Meningkatkan Kepuasan Pelanggan Di Madrasah Aliyah Terpadu (MAT) Darul Fallah Bogor," Islamic Management: Jurnal Manajemen Pendidikan Islam 2, no. 02 (2019): 133-151.
} 
dokumen berkaitan strategi pemasaran, data siswa, data pendidik dan tenaga kependidikan, dokumentasi kegiatan, dan arsip-arsip sekolah lainnya yang berkaitan dengan pemasaran jasa pendidikan berbasis budaya religius. Sedangkan data wawancara diperoleh dari hasil wawancara dengan kepala sekolah, Humas, dan orang tua wali murid.

Teknik pengumpulan data yang digunakan adalah observasi, wawancara, dan dokumentasi. Peneliti menggunakan analisis data model Miles dan Huberman, dengan tiga jenis kegiatan, yaitu reduksi data, penyajian data, dan penarikan kesimpulan/verifikasi sebagai suatu yang jalin-menjalin saat sebelum, selama, dan sesudah pengumpulan data dalam bentuk yang sejajar.

\section{HASIL DAN PEMBAHASAN}

Strategi bauran pemasaran yang dilakukan oleh SDIT Luqman Al-Hakim Internasional berbasis budaya religius adalah sebagai berikut:

\section{Produk (Product)}

Produk yang ditawarkan oleh SDIT Luqman Al-Hakim Internasional Yogyakarta adalah sekolah yang mengembangkan konsep pendidikan integral-holisis berbasis nilai-nilai ke-tauhid-an. Penerapan sekolah dengan konsep pendidikan integral-holistis berbasis nilai-nilai ke-tauhid-an diharapkan mampu membentuk karakter siswa yang kaffah (mendekati sempurna) dengan dibekali attitudes (sikap-sikap), skills (kecakapan-kecakapan) dan knowledge (ilmu pengetahuan). Kurikulum yang digunakan adalah kurikulum Pendidikan Holistik dan Integral (PHI), yang menggunakan konsep pendidikan islami, UK Curriculum dan kurikulum Diknas sebagai sumber referensinya Proses pembelajaran menekankan pada: kecerdasan spiritual, kecerdasan moral, kecerdasan intelektual, kecerdasan fisik, kecerdasan interpersola, kecerdasan kebudayaan, dan kecerdasan sosial.

\section{Tarif (Price)}

Tabel 1. Biaya Pendidikan di SDIT Luqman Al-Hakim Internasional Yogyakarta

\begin{tabular}{ll}
\hline Jenis Biaya & Jumlah \\
Pendidikan & Biaya \\
\hline Biaya Rutin & Rp.1.250.000 \\
Per & \\
Semester & \\
Biaya Rutin & Rp.855.000 \\
Per Bulan & \\
Biaya Rutin & Rp.100.000 \\
Per Tahun & \\
PDB & Rp.1.400.000 \\
Kit/Seragam & \\
\hline
\end{tabular}




\section{Lokasi (Place)}

SDIT Luqman Al-Hakim Internasional berlokasi di Jl. Karanglo No.2, Jogoragan Modalan, Banguntapan, Bantul, D.I. Yogyakarta 55198 (Timur Pasar Kotagede, Ringroad Barat), Lokasi dekat dengan rumah penduduk yang cukup representative dan kondusif untuk melaksanakan kegiatan pembelajaran. Luas tanah di SDIT Luqman Al-Hakim Internasional Yogyakarta adalah $2386 \mathrm{M}^{2}$ yang cukup luas untuk semua kgiatan pembelajaran peserta didik.

Tabel 2. Tempat/Lembaga Penunjang Pendidikan

\begin{tabular}{|c|l|l|l|}
\hline No. & \multicolumn{1}{|c|}{ Nama Lembaga/Tempat } & \multicolumn{1}{|c|}{ Alamat } & \multicolumn{1}{|c|}{ Jarak* $^{*}$} \\
\hline 1 & $\begin{array}{l}\text { Dinas Pendidikan, Pemuda, dan } \\
\text { Olahraga D.I. Yogyakarta }\end{array}$ & $\begin{array}{l}\text { Jl. Cendana No.9, } \\
\text { Yogyakarta }\end{array}$ & $2,35 \mathrm{Km}$ \\
\hline 2 & SDIT Salsabila 3 Banguntapan & $\begin{array}{l}\text { Jurugentong RT } \\
10 / \text { RW 34 }\end{array}$ & $0,45 \mathrm{Km}$ \\
\hline 3 & SD Qurrota Ayun & $\begin{array}{l}\text { Babadan, } \\
\text { Banguntapan }\end{array}$ & $0,76 \mathrm{Km}$ \\
\hline 4 & PBM Purbosiswo & Jl. Kemasan 39-A & $1,63 \mathrm{Km}$ \\
\hline 5 & PKBM Tamanan & $\begin{array}{l}\text { Jl. Imogiri Timur } \\
\text { Km. 6,5, Ngebleng }\end{array}$ & $1,75 \mathrm{Km}$ \\
\hline 6 & Museum Dewantara Kirti Griya & $-\quad \begin{array}{l}\text { KRKB Gembira } \\
\text { Loka, Jl. Kebun } \\
\text { Raya No.2 }\end{array}$ & $1,47 \mathrm{Km}$ \\
\hline 7 & Museum Gembira Loka & $\begin{array}{l}\text { Jl. Pangkalan Adi } \\
\text { Sucipto, Komp. } \\
\text { Lanud Adisucipto }\end{array}$ & $1,67 \mathrm{Km}$ \\
\hline 8 & $\begin{array}{l}\text { Museum TNI-AU Dirgantara } \\
\text { Mandala }\end{array}$ & & \\
\hline
\end{tabular}

*Jarak dari SDIT Luqman Al-Hakim Internasional Yogyakarta

4. Promosi (Promotion)

Sekolah melakukan promosi dengan cara membangun komunikasi dengan masyarakat, mendokumentasi segala kegiatan yang dilaksanakan yang kemudian dipublikasikan (melalui web, facebook, koran dan buletin), kerjasam dengan lembaga lain untuk mengadakan baksos, menyebarkan brosur, menerbitkan bulletin, talkshow kependidikan di Islamic Book Fair (IBF), sosialisasi ke PAUD/TK. iklan melalui radio, dan mengikuti berbagai perlombaan yang diadakan oleh pemerintah atau lembaga swasta lainnya. SDIT Luqman Al-Hakim Internasional melakukan bauran promosi, diantaranya: 1) Komunikasi pribadi (personal communication): a) Penjualan pribadi (personal selling), yaitu melakukan penjualan pribadi dengan menerapkan penerapan seragam, mengikuti perlombaan, mengadakan baksos, dan lain-lain. b) Peneropongan pasar 
(telemarketing), yaitu menargetkan pelanggan dari masyarakat muslim terutama menengah keatas karena pelayanan jasa Pendidikan di SDIT LHI harus diimbangi dengan kemampuan pelanggannya. c) Layanan pelanggan (customer service), yaitu menerapkan 5S (senyum, salam, sapa, salim, dan santun. d) Pelatihan pelanggan (training customer), yaitu parenting (pelatihan bagaimana mengasuh dan mendidik anak) yang dialksanakan 2 bulan sekali. e) Komunikasi dari mulut ke mulut (word of mouth), yaitu komunikasi melalui mulut ke mulut. 2) Periklanan (Advertising): a) Pembuatan dan penyebaran brosur, b) Radio (broadcast), c) Internet, d) Desain organisasi (corporate design), e) Publisitas (publicity).

\section{SDM (People)}

Pendidik dan tenaga kependidikan yang diterima di SDIT LHI sebagian besar memiliki standar kelulusan S1, dan ada beberapa yang memiliki standar kelulusan S2 atau sedang menempuh jenjang S2.

Tabel 3. Jenjang Pendidikan Tenaga Pendidik dan Kependidikan SDIT LHI

\begin{tabular}{|l|l|l|}
\hline No. & \multicolumn{1}{|c|}{ Jenjang Pendidikan } & Jumlah \\
\hline 1 & S2 & 3 \\
\hline 2 & S1 & 37 \\
\hline 3 & D3 & 3 \\
\hline 4 & SMA/SMK & 4 \\
\hline
\end{tabular}

\section{Bukti Fisik (Physical Evidence)}

SDIT Luqman Al-Hakim dalam menunjang proses pembelajar sudah mempunyai sarana dan prasarana yang lengkap.

Tabel 4. Sarana dan Prasarana SDIT Luqman Al-Hakim Internasional Yogyakarta

\begin{tabular}{|c|c|c|c|c|c|}
\hline \multirow[t]{2}{*}{ No. } & \multirow[t]{2}{*}{ Jenis Barang } & \multirow[t]{2}{*}{ Jumlah } & \multirow[t]{2}{*}{$\operatorname{Luas}\left(\mathbf{m}^{2}\right)$} & \multicolumn{2}{|c|}{$\begin{array}{c}\text { Kondisi Ruang dan } \\
\text { Tempat }\end{array}$} \\
\hline & & & & Baik & Rusak \\
\hline 1 & Ruang Kelas & 13 & 70 & $\checkmark$ & \\
\hline 2 & $\begin{array}{l}\text { Ruang Kepala } \\
\text { Sekolah }\end{array}$ & 1 & 9 & $\checkmark$ & \\
\hline 3 & Laboratorium IPA & 1 & & $\checkmark$ & \\
\hline 4 & $\begin{array}{l}\text { Ruang } \\
\text { Perpustakaan }\end{array}$ & 1 & 22 & $\checkmark$ & \\
\hline 5 & Masjid & 1 & 180 & $\checkmark$ & \\
\hline 6 & UKS & 1 & 12 & $\checkmark$ & \\
\hline
\end{tabular}




\begin{tabular}{|c|l|c|c|c|c|}
\hline 7 & Ruang Guru & 2 & 22 & $\checkmark$ & \\
\hline 8 & Gudang & 2 & 24 & $\checkmark$ & \\
\hline 9 & Ruang Makan & 1 & 108 & $\checkmark$ & \\
\hline 10 & Kamar Mandi & 12 & 3 & $\checkmark$ & \\
\hline 11 & Tempat Parkir & 3 & 175 & $\checkmark$ & \\
\hline 12 & Ruang Sirkulasi & 10 & 102 & $\checkmark$ & \\
\hline 13 & Kantin & 1 & 12 & $\checkmark$ & \\
\hline 14 & Post Satpam & 1 & 8 & $\checkmark$ & \\
\hline 15 & Tempat & 5 & 1400 & $\checkmark$ & \\
\hline 16 & bermain/Olahraga & & & & \\
\hline 17 & Rini Bank & 1 & 8 & $\checkmark$ & \\
\hline
\end{tabular}

\section{Proses (Process)}

Kurikulum yang digunakan di SDIT Luqman Al-Hakim Internasional adalah kurikulum Pendidikan Holistik dan Integral (PHI) yang menggunakan konsep pendidikan islami, UK Curriculum, dan kurikulum Diknas.

Kurikulum PHI (Pendidikan Holistik dan Integral) yang menggunakan konsep pendidikan Islami, UK Curriculum dan Kurikulum Dinas (Kurikulum 2013) menjadikan SDIT LHI sudah memenuhi Standar Nasional Pendidikan (SNP) dan menjadi sekolah dasar Internasional. Kurikulum ini mengutamakan proses pembelajaran yang mempunyai tiga kompetensi, yaitu: (1) Living Skills, yaitu kecakapan yang dibutuhkan untuk beradaptasi dalam kehidupan sehari-sehari. (2) Learning Skill, yaitu kecakapan untuk selalu dapat mengembangkan diri melalui proses belajar yang berkelanjutan. (3) Thingking Skills, yaitu kecakapan yang dibutuhkan saat berpikir memecahkan masalah dalam kehidupan sehari-sehari.

Implementasi budaya religius dilakukan sekolah melalui dimensi tauhid, dimensi syari'ah, dan dimensi akhlak yang terdapat dalam kurikulum, visi, misi, tujuan sekolah, program sekolah, dan proses pembelajaran. Keinginan pelanggan jasa pendidikan di SDIT LHI berdasarkan hasil wawancara dengan pengelola sekolah adalah pendidikan yang mengutamakan pendidikan agama dengan ditunjang pendidikan umum. Pendidikan agama disini bukan hanya pendidikan teori agama, namun pendidikan keagamaan (religius), yaitu pendidikan yang menjadikan anak memahami esensi beragama. Anak bukan hanya diajarkan beribadah (sholat, puasa, dan lain-lain) tapi juga berusaha dipahamkan esensi dari agama tersebut pada kehidupan sosial, seperti membantu orang lain, bersikap sopan dan ramah dengan orang lain, dan lain-lain,

Visi sekolah untuk membentuk generasi Islam yang berkarakter kuat, menguasai prinsip dasar keilmuan, dan berkontribusi untuk kebaikan dunia didukung dengan kurikulum PHI. Kegiatan ekstrakulikuler dan pengondisian lingkungan sekolah secara Islami (budaya religius) 
menjadi jalan mulus dalam merealisasikan kurikulm PHI. Budaya religius sebagai nilai jual lebih SDIT LHI mampu memenuhi kebutuhan pelanggan akan Pendidikan yang baik.

Berdasarkan wawancara tersetruktur kepada beberapa orang tua wali murid diketahui bahwa mereka mempercayakan anak-anaknya untuk menimba ilmu di SDIT LHI karena kurikulum berbasis budaya religius yang dipromosikan oleh sekolah. Selain itu, berdasarkan analisis data diketahui faktor yang mendukung pemasaran jasa pendidikan di SDIT LHI yaitu: a. Penerapan kurikulum PHI; b. SDM yang kompeten; c. Sarana pendidikan yang lengkap;d. Kegiatan promosi yang menggunakan banyak strategi; e. Lokasi sekolah yang mudah diakses; f. Prestasi yang cukup banyak di bidang umum dan keagamaan. Sedangkan faktor penghambatnya yaitu: a. Input peserta didik yang kurang karena SPP yang lumayan mahal; b. Tenaga pendidik tidak tetap; c. Persaingan dengan lembaga pendidikan lain; d. Manajemen pemasaran yang kekurangan personil; e. Perbedaan pemahaman terhadap tujuan sekolah antara pengelola sekolah dan orangtua.

\section{KESIMPULAN DAN SARAN}

Berdasarkan hasil analisis yang telah dilakukan, manajemen pemasaran jasa Pendidikan berbasis budaya religius dilakukan dengan menggunakan strategi marketing mix yaitu strategi pembauran pemasaran dengan menggunakan 7 unsur pemasaran: 1) Produk (product), 2) Tarif (Price); 3) Lokasi (place); 4) Promosi (Promotion); 5) SDM (People); 6) Bukti Fisik (Physical Evidence); 7) Proses (Process).

Faktor yang mendukung pemasaran jasa pendidikan di SDIT LHI yaitu: 1) Penerapan kurikulum PHI; 2) SDM yang kompeten; 3). Sarana pendidikan yang lengkap;4) Kegiatan promosi yang menggunakan banyak strategi; 5) Lokasi sekolah yang mudah diakses; 6) Prestasi yang cukup banyak di bidang umum dan keagamaan. Sedangkan faktor penghambatnya yaitu: 1) Input peserta didik yang kurang karena SPP yang lumayan mahal jadi perlu ditinjau kembali; 2) Tenaga pendidik tidak tetap sehingga pergantian tenaga pendidik akan menyulitkan pengelola sekolah dalam menyatukan pemikiran mengenai tujuan sekolah; 3) Persaingan dengan lembaga pendidikan lain yang sudah mulai memasukkan budaya religius ke dalam kurikulumnya; d. Manajemen pemasaran yang kekurangan personil sehingga tidak ada yang fokus dalam menyusun strategi pemasaran; 4) Perbedaan pemahaman terhadap tujuan sekolah antara pengelola sekolah dan orangtua.

\section{DAFTAR RUJUKAN}

Alma, Buchari, and Ratih Hurriyati. Manajemen Corporate \& Strategi Pemasaran Jasa Pendidikan. Alfabeta, 2008.

Amir, M Taufiq. "Dinamika Pemasaran.” Jakarta: PT. Raja Grafindo Persada (2005).

Chotimah, Chusnul, and Muhammad Fathurrohman. "Komplemen Manajemen Pendidikan Islam: 
Konsep Integratif Pelengkap Manajemen Pendidikan Islam.” Teras, 2014.

Daryanto, Hery Tarno. "Pengelolaan Budaya Dan Iklim Sekolah." Yogyakarta: Gava Media (2015).

Faizin, Imam. "Strategi Pemasaran Jasa Pendidikan Dalam Meningkatkan Nilai Jual Madrasah." Madaniyah 7, no. 2 (2017).

Faturrohman, Muhammad. "Budaya Religius Dalam Peningkatan Mutu Pendidikan: Tinjauan Teoritik Dan Praktik Kontekstualisasi Pendidikan Agama Di Sekolah.” Yogyakarta: Kalimedia (2015).

Hidayat, Ara, and Imam Machali. "Pengelolaan Pendidikan: Konsep, Prinsip, Dan Aplikasi Dalam Mengelola Sekolah Dan Madrasah.” Kaukaba, 2012.

Muhaimin, Nur Ali, Suti'ah, and Siti Lailan Azizah. Paradigma Pendidikan Islam: Upaya Mengefektifkan Pendidikan Agama Islam Di Sekolah. Remaja Rosdakarya, 2001.

Munir, M. "Manajemen Pemasaran Pendidikan Dalam Peningkatan Kuantitas Peserta Didik." Intizam, Jurnal Manajemen Pendidikan Islam 1, no. 2 (2018): 78-94.

Sahlan, Asmaun. Mewujudkan Budaya Religius Di Sekolah: Upaya Mengembangkan PAI Dari Teori Ke Aksi. UIN-Maliki Press, 2010.

Sarifudin, Sarifudin, and Rahendra Maya. "Implementasi Manajemen Pemasaran Jasa Pendidikan Dalam Meningkatkan Kepuasan Pelanggan Di Madrasah Aliyah Terpadu (MAT) Darul Fallah Bogor.” Islamic Management: Jurnal Manajemen Pendidikan Islam 2, no. 02 (2019): 133151.

Sihombing, Damos. "Prinsip-Prinsip Pemasaran.” Edisi Kedelapan. Jakarta: Erlangga (2001). 